\title{
An Explicit Approach of Natural Ventilation for Various Orientation of Wind Catcher Openings using CFD
}

\author{
V. Sivakumar ${ }^{1 \dagger}$, K.Visagavel ${ }^{2}$, A. Selvakumar ${ }^{2}$ and C. Jayavel ${ }^{2}$ \\ ${ }^{1}$ Department of Mechanical Engineering, M.A.M College of Engineering, Trichy, India \\ ${ }^{2}$ Department of Mechanical Engineering, Knowledge institute of Technology, Salem, India
}

†Corresponding Author Email: sivakumarpalapatti@gmail.com

(Received May 15, 2018; accepted July 18, 2018)

\begin{abstract}
Natural ventilation methods are far more efficient than the counter modern artificial methods and also it needs no energy for the ventilation. In this proposed system, angle of air flow at the entry is changed and it results in Air change per Hour (ACH) and the age of air changes. In accordance with the earlier studies, it has been concluded that there is a significant impact due to geometrical configuration in the wind catcher. Density of the air also supports this ventilation method, as cold air settles down due to high density and the hot air escapes through the top of the opening due to its lighter density. During this work, wind catcher's openings is altered in several angles for the improvement in the distribution of air. The evaluation is based on i) Downward air flow due to wind entry ii) Upward air flow due to temperature gradient. Geometry of the

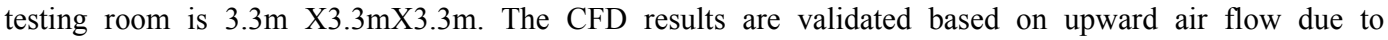
temperature gradient using the simulation software ANSYS. In the inlet openings, aperture angles such as 30degree, 45degree, 60degree and 75degree are tested. Results are approached analytically and to support analytical result simulation results are compared for better air velocity and uniform distribution.
\end{abstract}

Keywords: Ventilation; Window capture; Computational fluid dynamics; Less energy consumption.

\section{INTRODUCTION}

Indoor Air Quality (IAQ) is very essential for the comfort of human living particularly in high dense residential building. Ventilation is the process of introducing ambient air into the desired space deliberately to ensure a healthy and pleasant indoor conditions. In ancient days, buildings use passive or natural ventilation methods which was sufficient for air circulation, but the modern air tight houses require better air circulation methodologies, thus there is a great demand of inventing new technologies to drive the air mechanically.

Study made on wind catcher at different temperature shows that performance change due to wind catcher design imparts a major impact by Zhaleh. (2015). Building location according to geographical morphology determines the natural air flow potential and it is evident by the study Yunlong (2017). Ventilator Design is a critical parameter to increase air flow velocity and uniform air circulation inside the building as stated in the research paper by E.Hamzanlui (2011). An Outlet openings size and position is significantly increasing the air flow of cross- ventilation using wind catchers integrated into a single-zone isolated building in a neutral atmospheric boundary layer by Montazeri (2018). The four-sided wind catcher design has been instigated to catch wind from all directions without any rotating parts and providing continuous air flow inside the wind tower. Hence the wind catcher obtains better flow dynamics at the exit section of the wind catcher by Ali (2017).

The effect of wind flow direction was analyzed by varying with window opening angle from $-67.5^{\circ}$ to $67.5^{\circ}$ with respect to the windward and it includes the fluctuation of wind direction. In addition the geometry and size of wind catchers were investigated and the rate of air flow is significantly increased by varying with wind catcher's cross sectional area by Aryam (2015). Srinivasan (2017) studied and analysed about the missile with grid fins and the effect on flow drag using ANSYS. Godwin (2017) and Lakshmanan (2017) investigated about the optimum parameters for obtaining the best performance using alternate fuels of IC engines working under the current cooling system using Nanofluids. 


\section{PROBLEM IDENTIFICATION}

On a layman view, design of ventilation system may look a simple problem but it is complex due to the inherent, intricate behavior of fluid flow and turbulence. An opening in a room should have the following, water resistance, noise resistance, safe glazing, emergency egress Proper ventilation, Structural load resistance, solar heat resistance, security and economy.

When the size of the inlets and outlets are large and their positions are improper they form unsecured scenario, aids more noise, more light entering from outside to room, leads to temperature imbalances and on the other hand if the size are small they provide improper ventilation and less emergency exits.

More over the design of windows depends on building location and orientation, wind velocity and wind orientation, available wind disturbances in the near vicinity of home, indoor partitions and lay out, building dimensions and urban planning conditions.

\section{GEOMETRY ANALYSIS}

\subsection{Structure}

Wind catchers have varied designs and they are distinguished based on its purpose to serve and sometimes its purpose is compromised due to aesthetic reasons. In this method alignment of window is inclined along its vertical axis which is uncommon in conventional types. Also due to wind flow direction based on seismic report perpendicularity along horizontal wall is tilted against the flow of air and it is tested for common angles. Since studies show that convergent opening is much more efficient than regular parallel geometry convergent structure is used on the entry.

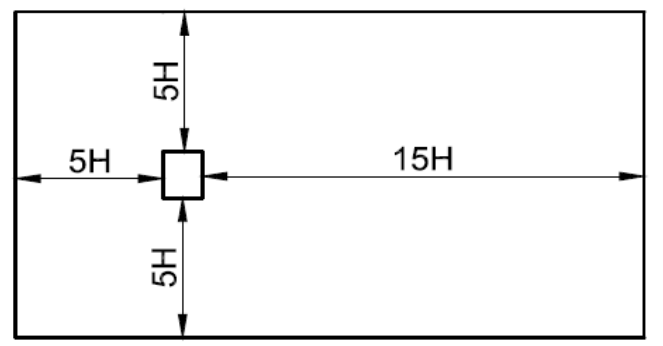

Fig. 1. Position of outlet at the top of the building

For the outlet standard placement is used since it has proved efficiency. This method focus more on drawing outside air and it is not possible if there is non-contiguous flow of air without obstacles. And if obstacles reduce the air velocity, accumulation heat inside may increase due to increased time of contact which result in air stagnation. Also geometry of tunnel along its sides is assumed to be symmetry during analysis. Also proposed position is shown in Fig.1.

\subsection{Property Values}

Pressure Coefficient $\mathrm{Cp}$ on all of the external surfaces of the building, determined by:

$\mathrm{C}_{\mathrm{p}}=\left(\mathrm{P}-\mathrm{P}_{0}\right) /\left(0.5 \rho \mathrm{V}^{2}\right)$

Where

$\mathrm{P}_{0}$ is the static pressure, $\mathrm{P}$ is the Density, $\mathrm{V}$ is the free stream velocity.

The turbulent kinetic energy profile $(k)$ and turbulent dissipation rate profile $(\varepsilon)$ are calculated using the equation

$\mathrm{U}(\mathrm{Z})=\mathrm{U}^{*}{ }_{\mathrm{ABL}} / k \ln \left[\left(\mathrm{Z}+\mathrm{Z}_{0}\right) / \mathrm{Z}_{0}\right]$

$k[\mathrm{Z}]=\mathrm{U}^{*} \mathrm{ABL}^{2} / \sqrt{\mathrm{CH}}$

$\Sigma(z)=\mathrm{U}^{*}{ }^{\mathrm{ABL}}{ }^{3} / k\left(\mathrm{Z}+\mathrm{Z}_{0}\right)$

Where $z$ is the height coordinate $(\mathrm{m}), z_{0}$ the aerodynamic roughness length $(\mathrm{m}), k$ the von Karman constant $(0.42), \mathrm{U}^{*}{ }_{\mathrm{ABL}}$ the atmospheric boundary layer friction velocity $(\mathrm{m} / \mathrm{s})$ and $C \mu$ is a constant (0.09).

\subsection{Analytical Approach}

Air distribution inside the room is calculated using the mass flow equation and its properties such as density pressure are calculated using continuity and momentum equation.

1) Continuity equation: $\operatorname{div} U=0$,

2) Momentum equation (Navier-Stokes equation): $\mathrm{dU} / \mathrm{dt}=\mathrm{g}-((1 / \rho) \operatorname{grad} \mathrm{p})+\operatorname{div}(2 \mathrm{vE})$,

3) Mass balance of an element using the equation: $(\rho p-\rho t / \delta t) V p+(\rho u) h x f A x-(\rho u) l x f A x=0$

Conventional structural performance is calculated using the above equations and they are compared with contour changes in the wind catcher as proposed above.

\subsection{Solver Methodology And Boundary Conditions}

The solver methodology for this optimization study is set as steady flow, incompressible ideal gas with domain inlet velocity is assumed to be of $1.2 \mathrm{~m} / \mathrm{s}$ and 5\% turbulence intensity is applied at the domain inlet. Zero static pressure is imposed at the domain outlet and walls are assumed to be adiabatic walls.

\section{SIMULATION RESULTS}

The proposed model is made with three convergent inclined openings at equal height with same opening areas. Wind catcher's inlet velocities were analyzed and were found to be as $1.66 \mathrm{~m} / \mathrm{s}$, and the uniform air flow is attained by changing the aperture angles in the inlet of wind catcher. By changing the angles of the air catcher's inlet, pressure and the velocity of the air changes in the room as shown in Figs 2 and 3. 


\subsection{Case (i)}

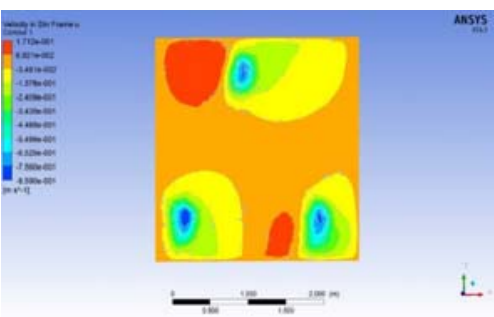

Fig. 2(a) Velocity distribution at 5 feet (Middle of the room)

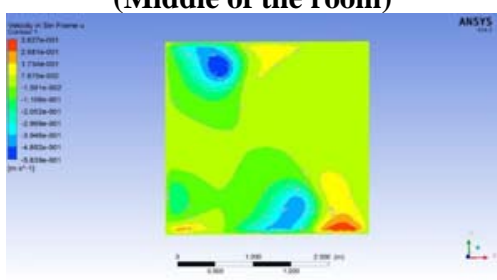

Fig. 2(b) Velocity distribution at 3feet from the front wall

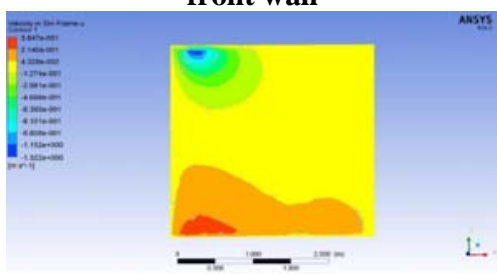

Fig. 2(c) Velocity distribution at 3feet from the rear wall

Fig. 2.Wind Capture angle is $75^{\circ}$

\subsection{Case (ii)}

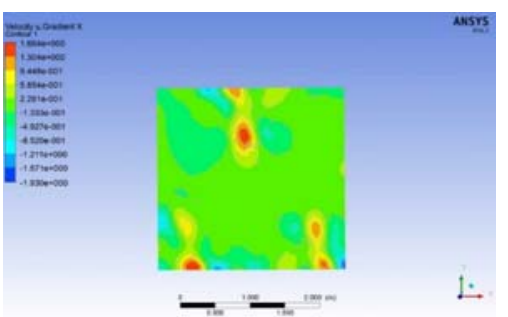

Fig. 3(a) Velocity distribution at 5 feet (Middle of the room)

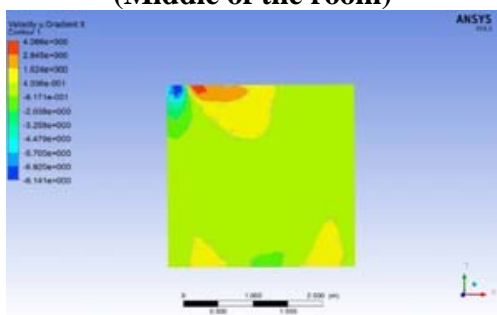

Fig. 3(b) velocity distribution at 3feet from the front wall

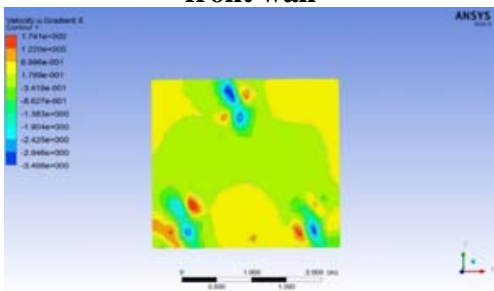

Fig. 3(c) Velocity distribution at 3feet from the rear wall

Fig. 3.Wind Capture angle is $60^{\circ}$

\section{CONCLUSION}

In this work, a new design is made for the ventilation of the building's interiors by changing the wind catcher's angle. The proposed model is suitable for the four-sided wind catcher and it improves uniform distribution of air. Moreover, the proposed model has the advantage that it does not contain any rotating parts and it is simply a static design at the interior of the wind catcher. The internal geometry of the proposed wind catcher aperture is based on the dynamics and the characteristics of the incoming wind at the inlet section. Consequently, the desired conditions of velocity and pressure can be obtained.

\section{REFERENCES}

Hedayat, Z., A., Bert, A. Belmans and M. Hossein. Ayatollahi (2015), Performance assessment of ancient wind catchers - an experimental and analytical study- Energy Procedia 78 -25782583.

Yunlong P., Z. Gao, W. Ding (2017) An Approach on the correlation between Urban Morphological Parameter and ventilation performance, Energy Procedia 142 2884-2891.

Hamzanlui, E., S. Moghaddama, S. Amindeldar (2011) New approach to natural ventilation in public buildings inspired by Iranian's traditional wind catcher, Energy Procedia 21, 45-52.

Montazeri, H. and F. Montazeri (2018) CFD simulation of cross-ventilation in buildings using rooftop wind catchers: Impact of outlet openings, Renewable Energy 118, 502-520.

Ali, A. and A. Balabel (2017) A new modern Design of four-sided Wind catcher for Natural Ventilation in Residential Building in Saudi Arabia" International Journal of Applied Environmental Sciences, Volume 12, Number 1, 27-36.

Aryam H. G., M. Dehnavi, (2015) The Effect Of Plan Size In Wind Catcher On Its Ventilation Rate, Research Gate, Volume-2, Issue-1.

Srinivasan, R., V. Vijayan and K. Sridhar (2017) Computational Fluid Dynamic Analysis of Missile with Grid Fins Journal of Applied Fluid Mechanics, Vol. 10, Special Issue, 33-39.

Godwin Antony, A., S. Dinesh, K. Rajaguru and V. Vijayan (2017) Analysis and Optimization of Performance Parameters in Computerized I.C. Engine Using Diesel Blended with Linseed Oil and Leishmaan's Solution, Mechanics and Mechanical Engineering 21(2) 193-205.

Lakshmanan, P., P. Kaliyappan, M. Ranjithkumar, K. Aravinth, D. Vakkachan, C. Moorthy and S. Kumar (2017) An Experimental Investigation to Study the Performance and Emission Characteristics of Chicken Fat Oil Fuelled DI Diesel Engine, Journal of Applied Fluid Mechanics 10, Special Issue, 85-91. 